\title{
Psychological aspects of pregnancy denial in a 13-year-old girl
}

\author{
Oddo-Sommerfeld S, Schulze S, Sommerlad S, Kämpf AK, Cholemkery H and Louwen F \\ Department of Obstetrics and Gynecology, University Hospital Frankfurt, Germany
}

\begin{abstract}
Pregnancy denial has a higher incidence than commonly supposed. So far psychological explanations rely on observations and interviews from individual cases. The presented case deals with a 13-year old mother with denied pregnancy, admitted to our department immediately after the birth of a healthy, mature infant. She was treated and observed interdisciplinary and for the first time we used psychometric testing in addition to medical and psychological treatments. Neither the psychological anamnesis nor test-psychometric results revealed a mental disorder. Some accentuated personality traits can explain the phenomenon to a small degree. However we adopt the idea of mental defence mechanisms, mainly projective identification, to explain the denied pregnancy in our case. The psychological processes of pregnancy denial thus become comprehensible and we derive suggestions for screening of at risk populations.
\end{abstract}

\section{Introduction}

With a prevalence of 1:475 [1] pregnancy denial is a relatively frequent event [2]. According to recent statistics, there are around 1600 cases of pregnancy denial in Germany every year [3]. In one of 2455 cases, pregnancy is denied until date of delivery [1]. Thus, the phenomenon of pregnancy denial occurs more often than naturally occurring triplet-pregnancies (incidence 1:7255) [1,4]. The proportion of affected women below the age of 30 years is extremely low $(1,75 \%$ in living born infants) [5], so that the presented case of a 13-year old mother constitutes a rarity. Neither casuistries [6-8] nor studies with larger sample sizes $[2,9,10]$ reveal specific evidence for underlying personality profiles or specific living conditions that had been suggested in previous research $[11,12]$. In one study [10], the following predictors of pregnancy denial reached statistical significance: "early and late phase of reproduction (age $<18$ and $>35$ years), "no migration background", "unstable relationship" and "critical social situation". However, these results do not allow predictions in individual cases, nor do they provide guidance on psychological processes involved in pregnancy denial. A recent case history reported pregnancy denial in one patient with schizophrenia who suffered from Cotard's syndrome after delivery [13]. Another casuistry by Sar et al. [14] reported an acute dissociative reaction in a young woman with pregnancy denial in which the neonate died afterwards. However, Dorsch et al. [3] point out that neonaticide is rare after pregnancy denial and occurs in 20-40 cases of a maximum caseload of 1600 denied pregnancies in Germany [16-20].

One possible explanation with regard to pregnancy denial focuses on the two defence mechanisms repression and projective identification [21]. Based on this model, denied pregnancy could be explained by an overstraining reality, such as the perception of symptoms of gravidity or the hypothesis of being pregnant. This requires the unconscious activation of defence mechanisms for the protection of psyche [12]. Due to the superficial accomplishment, excessive demands can be sustained. Depending on individual personality structure and biographical experiences, certain defence mechanisms are preferred. It is assumed that there is a fluent transition between defence mechanisms and emotion regulation strategies $[9,23,24]$. Furthermore Dorsch et al.
[3] assume that pregnancy denial can be favoured by deficits in emotion regulation- and problem-solving-strategies without meeting criteria for psychological disorder, e.g. personality disorders.

In the presented case, medical and psychological diagnoses and treatment are described. Additionally, psychometric tests were used to identify psychological characteristics. Results are presented in table 1.

\section{Casuistry}

In this article, we describe the case of a 13- year old first-time mother with denied pregnancy. For the first time gynaecological and psychosomatic aspects of medical examination as well as the results of psychometric testing are integrated in reviewing the case.

The 13-year old patient, originating from the Benelux countries with very good knowledge of German was examined in the delivery room in the evening hours as a case of emergency. She was accompanied by her teacher and surrounded by several police officers. Previously, the rescue service announced the admission of a 13-year old girl, who had just given birth to a mature infant during a school field trip to our city (Germany). Spontaneous delivery took place unsupported and unaccompanied on a youth hostel toilet. In terms of paediatric aspects, the infant was born mature and without any pathological anomalies. Upon arrival the female infant was admitted to the NICU. Using the "Petrussa-Score", gestational age was estimated at 40 weeks. The infant weighed $3100 \mathrm{~g}$, body length was $51 \mathrm{~cm}$ and the head circumference was $34 \mathrm{~cm}$, which is equivalent to the $10^{\text {th }}-50^{\text {th }}$ percentile at 40 weeks gestation. Due to initial hypothermia and bradycardia, the infant

Correspondence to: Schulze S, Department of Obstetrics and Gynecology, University Hospital Frankfurt, Germany, E-mail: Sally.Schulze@kgu.de

Key words: pregnancy denial, unnoticed pregnancy, mental defense mechanisms, psychological stress, personality

Received: December 13, 2017; Accepted: December 27, 2017; Published: December 29, 2017 
Table 1. Psychological test instruments

\begin{tabular}{|c|c|c|}
\hline Instrument & Construct & Subscales \\
\hline \multicolumn{3}{|l|}{ General psychopathology } \\
\hline $\begin{array}{l}\text { Youth Self Report (YSR) 11-18 [10], Child Behaviour } \\
\text { Checklist (CBCL) 4-18 [11] }\end{array}$ & $\begin{array}{l}\text { Behavioural and emotional problems } \\
\text { (self- and external assessment by parents and partner) }\end{array}$ & $\begin{array}{l}\text { Social withdrawal, physical complaints, anxiety and } \\
\text { depression, social problems, } \\
\text { schizoid/delusional symptomatology, } \\
\text { attention deficits, dissocial behaviour, aggressive behaviour }\end{array}$ \\
\hline \multicolumn{3}{|l|}{ Delivery and mother-child-relationship } \\
\hline Impact of Event Scale, revised version (IES-R) [12] & Assessment of psychological strain & Intrusion, avoidance, hyperreagibility \\
\hline Postpartum Bonding Questionnaire (PBQ) [13] & $\begin{array}{l}\text { Questionnaire for assessment of relationship disorders } \\
\text { concerning mother and child }\end{array}$ & $\begin{array}{l}\text { Delayed bonding, rejection and anger, anxiety, risk of child } \\
\text { abuse }\end{array}$ \\
\hline \multicolumn{3}{|l|}{ Emotional regulation, temperament and character } \\
\hline $\begin{array}{l}\text { Fragebogen zur Erhebung der Emotionsregulation bei } \\
\text { Kindern und Jugendlichen (FEEL-KJ) [14] }\end{array}$ & Strategies for regulation of anxiety, grief and anger & $\begin{array}{l}\text { adaptive emotional regulation-strategies: problem-oriented } \\
\text { action, scattering, mood raising, accepting, forgetting, re- } \\
\text { evaluation, cognitive problem-solving, } \\
\text { maladaptive emotional regulation-strategies: } \\
\text { giving up, aggressive behaviour, withdrawal, self- } \\
\text { devaluation } \\
\text { other subscales: expression, social support, emotion-control }\end{array}$ \\
\hline \multirow{2}{*}{$\begin{array}{l}\text { Junior Temperament und Charakter Inventar (JTCI) 12-18 } \\
{[15]}\end{array}$} & \multirow[t]{2}{*}{ Temperament and character } & $\begin{array}{l}\text { Temperament scales: } \\
\text { Curiosity behaviour, loss prevention, reward dependence, } \\
\text { inertia }\end{array}$ \\
\hline & & $\begin{array}{l}\text { Character scales: } \\
\text { Self-steering ability, cooperativeness, self-transcendence }\end{array}$ \\
\hline
\end{tabular}

remained at the adjacent NICU for observation and received antibiosis i.v.

Consultation of the police was performed routinely by the rescue service, because of the mothers' age. Upon arrival, general situation and circumstances of pregnancy were uncertain. Therefore anamnesis was obtained in the presence of police officers. During this anamnesis, initial suspicion of conception under non-consensual circumstances or other sexual abuse was ruled out. Despite the circumstances, the patient was in a good general condition and denied any knowledge regarding a possible pregnancy even during the last weeks. Within the last days before delivery, she suffered from abdominal pain, which she interpreted as general menstrual pain. As she reported, she did not notice the delivery until the child's head pushed through. After childbirth, her teacher called the rescue service, which performed the cutting of the umbilical cord. Birth of the placenta took place at the hospital. The mother did not suffer from specific injuries from childbirth. It could be clarified quickly that the infant originated from an amicable partnership with a 17-year old boy. At the patients' request, her parents and partner were informed and arrived on the following day. Our young mother immediately asked for contact with her baby.

The youth welfare office of Germany and at her home country needed to be informed about the childbirth, even though the family situation upon arrival of her parents was good and seemed to provide sufficient protection and support.

The patient reported that she had not been aware of her pregnancy. Weight gain over the last nine months was explained by increased food intake according to the patient, her parents and her partner. She was not overweight. The mother reported that she had repeatedly and explicitly mentioned the possibility of pregnancy to the daughter, which the daughter had always denied. They had agreed to do sports workouts for weight reduction. The patient reported occasional bleeding and calf cramps but no pregnancy-specific symptoms. Alcohol and nicotine were occasionally consumed during pregnancy. Neither preventive examinations during pregnancy nor medical or gynaecological contacts were performed. No additional diagnoses, past surgeries and/ or previous mental illness were reported. The menarche took place at the age of 12 years.
The patient's living conditions were prototypical for a middle-class family. The patient lived with her parents in a neighbouring European country with eleven-year-old twin siblings (sister and brother). The relationship with the 17-year-old partner, who is the child's father and had been the first sex partner, had existed for 18 months. They had consensually been sexually active for about a year already. Condoms were used for contraception. Oral contraception had been addressed several times by the mother, but had been rejected by the patient.

In the course of the patient's psychosomatic anamnesis, as well as the exploration of the parents and the partner on the morning after the birth, there were no symptoms of acute stress reaction. The psychosocial situation with elevated socioeconomic status was regarded as very good. The patient did not show any psychopathology before giving birth. This was confirmed by the responsible school psychologist in her home country, who we consulted the day after the birth. Other than phases with reduced motivation for school, she had no problems. The school psychologist had not noticed the pregnancy. The patient and her partner seemed embarrassed in the conversation and described feelings of guilt and shame towards the parents. They were aware that they had worried the parents. Both of them had difficulties talking about the situation, yet they were both adequately oriented, conscious, not suicidal, and sufficiently emotionally responsive. A future with a child was initially difficult to imagine for the young couple. Release for adoption was discussed with the couple and the patients' family. In contact with the baby the patient and her parents were caring and emotionally involved. On the second day postpartum, the patient and her parents' decided to take the daughter into their family. After an inconspicuous treatment course of a few days, the child was discharged from NICU with her mother. Careful consideration, self-reflection and deliberation with her family led the patient to decide to wean two days postpartum (supported medically with Dostinex).

In addition to the obstetric care and psychosomatic exploration, the following psychological tests were applied two days postpartum to capture the mental state, emotional regulation strategies as well as temperament- and character features. The tests were used to detect underlying psychological causes of the pregnancy denial. In particular, 
temperament and character tests can provide hypotheses on affinity to particular defence mechanisms.

\section{Test results}

The questionnaires for the assessment of general psychopathology (YSR 11-18 [15] and CBCL 4-18 [16]; self and external assessment) indicate inconspicuous values. Results of the trauma screening questionnaire (IES-R) [17] and mother-child relationship questionnaire (PBQ) [18] show neither psychopathology due to delivery nor dysfunctional relationship building tendencies between mother and child. Self-assessment regarding the use of adaptive and mal-adaptive regulation strategies for dealing with anxiety, anger and grief indicate an adequate emotion-regulation. These strategies were assessed with FEEL-KJ [19]. Regarding self and external assessment of temperament and character features (JTCI 12-18) [20] slightly below and above-average values were observed. The patient described her temperament as easily accessible in social context, i.e. dominated by strong dependence on reward. Furthermore, she considered herself as easily intrinsically motivated and seemed to have a high inertia-She described her character as principled with a high level of cooperation. Within the external assessment by her parents, the patient was described as rationalistic (low values on the scale self-transcendence). Additionally, the patient's father described her as purposeful, i.e. with high levels of executive functioning. The test manual recommends a combined interpretation of all personality scales [20]. The combination of increased self-steering ability and low values regarding the selftranscendence suggests a consistent ability to self-regulate emotions.

\section{Discussion}

This case is the first documentation psychometric data, of psychopathological aspects, personality traits and emotion-regulation strategies in a 13-year-old girl after pregnancy denial. Neither the clinical assessment, nor the psychometric testing revealed any psychopathological disorders. Psychosis-related pregnancy denial did not occur in the case of our 13-year old patient. The patient shows two to three of the four risk factors for pregnancy denial according to Wessel et al. [21]. She is in the reproductive age and has no migrant background. Regarding her young age, the relationship stability can be judged as relatively high due to the duration of 18 months. However, it should be noted that in particular because of the young age the relationship stability is uncertain in the long term. A critical social situation has not been determined. In contrast, the patient seemed to be raised into an economically stable, loving family. This impression was sustained upon several follow-up contacts. The parents' reaction was very understanding. They immediately agreed to provide assistance and were very future-oriented concerning the baby.

In addition to the casuistry studies of Lieb et al. [6] we have found some differentiating personality traits that support the psychodynamic model of denied pregnancy [21] due to mental defence mechanisms, repression and projective identification.

By activation of the defence mechanism repression, awareness of the predominant pregnancy or even fertility is removed from the conscious and preconscious. Instead the wish of not being pregnant takes the place of this knowledge. Projective identification then entails the unconscious split off one part of the self and project ones own thoughts and feelings onto others. This may explain the inclusion of the social environment in the pregnancy denial. Both relatives and medical staff are unconsciously motivated to adopt an alternative explanatory model for typical signs of pregnancy [21].
The process of pregnancy denial can be conceptualized in three stages. In the first stage, the pregnant woman has "the deep subjective conviction of not being pregnant" [21, p. 51], as fertility is denied [7,9] or a strong desire of not being pregnant (repression). This basic attitude forms the foundation for pregnancy denial and typical accompanying symptoms. Secondly, the communication partners are unconsciously put under pressure by projective identification and are thus influenced to adopt the attitude of the pregnant woman. During the third and final stage, relatives and medical staff start showing inner experience and behaviour, which meets the wishes of the woman undergoing pregnancy-denial. Alternative explanatory models for occurring pregnancy symptoms are offered or adopted, so that denial of pregnancy remains intact.

The patient's high social responsiveness (reward dependence) could be a trait that leads to adaptation to a socially desired child bearing age and the non-pregnant attitude. The increased persistence and the firmness of the principles allowed the patient to hold on to the conviction of not being pregnant. Despite symptoms of pregnancy and confrontation by the mother, the patient maintained denial. The mental defences of the conflict did not collapse. The mother followed the patient's attitude and regulated her unconscious conflict through the sports offer. With the real situation of birth, the collapse of the denial was inevitable.

Knowledge, which has been repressed from the consciousness, but has been existent in the unconscious permanently, may explain why the patient did not experience the delivery as traumatic and was able to develop surprisingly quickly an adequate relationship with her infant. Pregnancy and motherhood were already anticipated unconsciously. Moreover, she received a lot of support and understanding, which relieved her from her initial shame and guilt. Kenner et al. [22] assume that body and mind likely have positive feedback loops that reinforce the woman's conscious misperception of her actual condition e.g. no morning sickness, misperception of quickening.

To verify whether the detected deviation of the personality traits is not just valid for this individual case of pregnancy denial, but generally applicable in the understanding of denied pregnancy, further research is needed. In the future, these findings could be integrated to a preventive screening procedure during first visits to the gynaecologist.

Even though no psychopathology was observed either in our patient or her family, they received further psychological support at our clinic and subsequently in the home country. According to the patient's family, psychological and medical support in our interdisciplinary team represented an essential foundation to ensure a good adaption to the new and challenging situation. From time to time the mother reported information about her current living situation to and her mother-child relationship kept developing well.

As the present case illustrates, in a good general resource setting the early application of psychological support positively affects transition into unplanned parenthood without the occurrence of psychological stress symptoms.

Accordingly close individual psychological support should be mandatory within the obstetric care after pregnancy denial. The presented case leads us to the advise medical staff, teachers and parents to inform youth about the phenomenon to prevent pregnancy denial. This applies in particular to very young and seemingly very autonomous girls. 


\section{References}

1. Wessel J, Buscher U (2002) Denial of pregnancy: population based study. BMJ 324: 458. [Crossref]

2. Beier KM, Wille R, Wessel $\mathrm{J}$ (2006) Denial of pregnancy as a reproductive dysfunction: A proposal for international classification systems. Journal Psychosom Res 2006, 61: 723-30. [Crossref]

3. Dorsch V, Jelden N, Rohde A (2017) Neonatizid als mögliche Folge einer negierten Schwangerschaft. Rechtsmedizin 27: 295-307.

4. Stauber M, Weyerstahl T (Hrsg) (2005) Gynäkologie und Geburtshilfe. 2. Aufl. Stuttgart: Thieme; 471 .

5. WHO (2015) http://data.euro.who.int/hfadb/tables/tableB.php?w=1280\&h=1024 Abfrage am 15.9.2015 aus der Datenbank der WHO.

6. Lieb M, Hummel I, Fürst S, Baghai TC, Mokhtari-Nejad R, et al. (2012) Psychotische und nicht-psychotische Verleugnung der Schwangerschaft. Fortsch Neurol Psychiat 80: 276-9.

7. Struye A, Zdanowicz N, Ibrahim C, Reynaert C (2013) Can denial of pregnancy be denial of fertility? A case discussion. Psychiatr Danub 25: 113-7. [Crossref]

8. Di Giacomo E, Calabria M, Colmegna F, Pucci B, Clerici M (2017) A case report highlights the neglect problem of pregnancy denial. European Psychiatry 41: 901.

9. Brezinka C, Huter O, Biebl W, Kinzl J (1994) Denial of pregnancy: obstetrical aspects. J Psychosom Obstet Gynaecol 15: 1-8. [Crossref]

10. Wessel J, Gauruder-Burmester A, Gerlinger C (2007) Denial of pregnancy-characteristics of women at risk. Acta Obstet Gynecol Scand 86: 542-546. [Crossref]

11. Green CM, Manohar SV (1990) Neonaticide and hysterical denial of pregnancy. Br J Psychiatry 156: 121-123. [Crossref]

12. Bonnet C (1993) Adoption at birth: prevention against abandonment or neonaticide. Child Abuse Negl 17: 501-513. [Crossref]

13. Kuppili PP, Gupta R, Pattanayak RD, Khandelwal SK (2017) Delusional denial of pregnancy: Unique presentation of Cotard's syndrome in a patient with schizophrenia. Asian J Psychiatr 30: 26-27. [Crossref]
14. Sar V Md, Aydin N Md, van der Hart O, Steven Frankel A, Sar M, et al. (2017) Acute dissociative reaction to spontaneous delivery in a case of total denial of pregnancy: diagnostic and forensic aspects. J Trauma Dissociation 18: 710-719. [Crossref]

15. Döpfner M, et al. (Hrsg) (1995) Handbuch: Fragebogen für Jugendliche. Forschungsergebnisse zur Deutschen Fassung der Youth Self-Report Form (YSR) der Child Behavior Checklist (CBCL/4-18).2. Aufl. Köln: Arbeitsgruppe Kinder., Jugendund Familiendiagnostik (KJFD).

16. Döpfner M, et al. (Hrsg) (1994) Handbuch: Elternfragebogen über das Verhalten von Kindern und Jugendlichen. Forschungsergebnisse zur Deutschen Fassung der Child Behavior Checklist (CBCL/4-18).2. Aufl. Köln: Arbeitsgruppe Kinder., Jugend- und Familiendiagnostik (KJFD).

17. Maercker A, Schützwohl M (1998) Erfassung von psychischen Belastungsfolgen: Die Impact of Event Skala-revidierte Version. Diagnostica 44:130-141

18. Brockington IF, Oates J, George S, Turner D, Vostanis P, et al. (2001) A screening questionnaire for mother-infant bonding disorders. Arch Women Ment Hlth 3: 133-140

19. Grob A, et al. (Hrsg) (2005) Fragebogen zur Erhebung der Emotionsregulation bei Kindern und Jugendlichen (FEEL-KJ). 1. Aufl. Bern: Verlag Hans Huber.

20. Goth K, et al. (Hrsg) (2005) Das Junior Temperament und Charakter Inventar (JTCI).1 Aufl. Göttingen: Hogrefe.

21. Wessel J, Endrikat J, Kästner R (2003) Projektive Identifizierung und Schwangerschaftsverdrängung - Überlegungen zu Ursachen und Hintergründen der auch ärztlicherseits nicht erkannten Schwangerschaft. Z Geburtsh Neonatol 207: 48$53-20$

22. Kenner WD, Nicolson SE (2015) Psychosomatic disorders of gravida status: False and denied pregnancies. Psychosomatics 56: 119-128. [Crossref]

23. Sandoz P (2011) Reactive-homeostasis as a cybernetic model of the silhouette effect of denial of pregnancy. Med Hypotheses 77: 782-5. [Crossref]

24. Kaplan R, Grotowski T (1996) Denied pregnancy. Aust N Z J Psychiatry 30: 861-863. [Crossref]

Copyright: (2017 Oddo-Sommerfeld S. This is an open-access article distributed under the terms of the Creative Commons Attribution License, which permits unrestricted use, distribution, and reproduction in any medium, provided the original author and source are credited. 